\title{
CONTRIBUIÇÕES DA CONCEPÇÃO CONSTRUTIVISTA PARA ÁREA EDUCACIONAL: COMPARTILHANDO SABERES... NOVOS OLHARES.
}

\author{
Mariza Fortuna, Rosana Meire Cazadei, Carmen Lúcia Dias \\ Universidade do Oeste Paulista - UNOESTE, Programa de Pós Graduação em Educação, Presidente Prudente, SP. \\ Email: pedagoga.mariza@hotmail.com; rosanacazadei@hotmail.com
}

\section{RESUMO}

A educação tem função de transmitir aos alunos o saber sistematizado, o conhecimento científico produzido historicamente que os instrumentalize para atuar na sociedade de forma crítica, concreta e consciente. Ao longo dos anos, a sociedade passou por diversas mudanças, pois é dinâmica e em constante movimento, porém o sistema educacional brasileiro não conseguiu acompanhar as alterações essenciais na educação formal do indivíduo. Nesse sentido, este artigo objetiva apresentar as contribuições da teoria piagetiana na área educacional, buscando esclarecer alguns equívocos sobre essa teoria, formar e informar os professores acerca de sua utilização na prática pedagógica, pois permite maior aproximação do papel social escolar. Para tanto, utilizamos, como aporte teórico epistemológico autores que discutem os conceitos-chave da teoria construtivista de Jean Piaget. A partir dessas discussões, é possível confirmar a relevância da teoria piagetiana na área educacional, promovendo o conhecimento e o desenvolvimento humano em todas suas possibilidades.

Palavras-chave: Prática pedagógica. Processo ensino-aprendizado. Papel social da escola. Contribuições da teoria Construtivista. Formação integral do aluno.

\section{CONTRIBUTIONS FROM THE CONSTRUCTIVIST CONCEPTION TO EDUCATIONAL AREA: SHARING KNOWLEDGE ... NEW LOOKS.}

\begin{abstract}
Education has the function of transmitting to the students the systematized knowledge, the historically produced scientific knowledge that will instrumentalize them to act in society in a critical, concrete and conscious way. Over the years, society has undergone several changes, since it is dynamic and in constant movement, but the Brazilian educational system has not been able to keep up with the essential changes in the individual's formal education. In this sense, this article aims to present the contributions of the Piagetian theory in the educational area, seeking to clarify some misconceptions about this theory, to train and inform teachers about its use in pedagogical practice, since it allows a closer approximation of the school social role. For that, we use, as an epistemological theoretical contribution, authors who discuss the key concepts of Jean Piaget's constructivist theory. From these discussions, it is possible to confirm the relevance of Piagetian theory in the educational area, promoting knowledge and human development in all its possibilities.
\end{abstract}

Keywords: Pedagogical practice. Teaching-learning process. Role of the school. Contributions of the Constructivist theory. Integral formation of the student. 


\section{INTRODUÇÃO}

A educação é uma necessidade humana para garantir às presentes e às futuras gerações acesso ao conhecimento produzido pela humanidade, e para formar cidadãos críticos, participativos, autônomos e com capacidade de criação. A escola, desde seus primórdios, focavase na disciplina, na ordem, e o professor era tido como o detentor do conhecimento, que "despejava" informações aos discentes, e estes últimos eram vistos como "tábula rasa", que pouco ou nada sabiam, somente recebiam as informações, sendo preciso memorizá-las.

Piaget, em suas pesquisas, que não eram voltadas à área educacional, buscava compreender como o ser humano sai de uma condição de menor conhecimento para uma de maior conhecimento (PETRUCl, 1997). Observou que o ser humano possui três tipos de estruturas programadas: o órgão reprodutor, em que estão as parcialmente programadas; o sistema nervoso, no qual estão as nada programadas; e as estruturas mentais. Isso implica afirmar que o ser humano pode ou não se desenvolver, e isso dependerá de sua maturação e da relação que estabelecer com o meio (CHIAROTTINO, 1988). A estrutura nada programada do indivíduo é propícia para aprender, e depende de sua maturação e de seu contato com o meio. Para tanto, é preciso superar a dicotomia meio $X$ organismo, fundamental para essa interação.

$\mathrm{Na}$ acepção de Piaget, a aprendizagem não é uma atividade qualquer, é algo planejado pelo professor, com estratégias que desenvolvam no educando um conflito cognitivo; necessidade que o fará buscar respostas e soluções para situações problema diversas (DIAS, 2016).

A teoria piagetiana contrapõe-se ao modelo em que o aluno recebe de forma passiva o conhecimento transmitido pelo professor, porque para aprender é necessário agir sobre o objeto, em uma construção progressiva da maturação biológica e das condições físico-sociais.

Nesse sentido, as implicações pedagógicas dos estudos de Piaget coadunam com a ideia de que o professor, entendendo a maneira como seu aluno aprende, e consequentemente desenvolve a cognição, consegue elaborar intervenções que favoreçam a aquisição do conhecimento.

O equilíbrio (assimilação de um novo estímulo) pode ser encontrado nas situações em que, por exemplo, uma criança, ao experienciar uma nova situação tenta assimilá-la a um esquema já existente e caso isso ocorra com sucesso, terá alcançado naquele momento o equilíbrio, em relação àquela situação estimuladora particular. Caso a criança não consiga assimilar, visará à acomodação, modificando um esquema ou criando um esquema novo, na busca pelo equilíbrio (PILETTI, 2011, p. 70).

Este estudo justifica-se por apontar que a função da escola não deve estar apenas atrelada à transmissão de conteúdos, mas ir além, conseguir formar cidadãos autônomos, críticos, conscientes de seu verdadeiro papel na sociedade vigente. Ao professor, cabe a tarefa de assumir o importante papel que tem nesse processo de ensino e de aprendizagem, dominando os conteúdos acumulados historicamente a fim de promover as mediações necessárias na construção do conhecimento, entendendo como o indivíduo aprende e se desenvolve, sendo essa uma condição básica durante a formação dos alunos.

O objetivo deste artigo é apresentar as contribuições da teoria piagetiana na área educacional, procurando esclarecer alguns equívocos sobre essa teoria, bem como formar e informar os professores a respeito da utilização dessa teoria na prática pedagógica, uma vez que permite maior aproximação do papel social da escola.

\section{METODOLOGIA}

A referente pesquisa bibliográfica (SALVADOR, 1991), teve como aporte teórico epistemológico, autores que propõem uma discussão relativa aos conceitos da teoria piagetiana. Esses conceitos, quando bem entendidos e esclarecidos, podem contribuir para uma prática 
pedagógica mais eficiente em sala de aula. Para a avaliação do material impresso, utiliza-se o método de Análise de Conteúdos (BARDIN, 2006).

\section{DISCUSSÃO}

A teoria de Jean Piaget trouxe muitas contribuições para o trabalho em sala de aula, embora não tenha como objetivo principal os espaços escolares. Durante muitos anos, essa teoria foi entendida de maneira equivocada pelos docentes.

Tal assertiva é possível, pois os professores acreditam que a teoria construtivista de aprendizagem é um método, quando na se trata de uma concepção que busca entender como a criança aprende. Nas palavras de Chiarottino "O objetivo primordial de Piaget era o de solucionar a questão do conhecimento: Como é possível alcançar o conhecimento?" (1988, p. 31). Em suas investigações, Piaget não almejava renovar métodos de ensino ou debater questões educacionais, mas sim entender o funcionamento do cérebro humano. Petruci escreve: "Na verdade, sabe-se que Piaget tinha como preocupação primordial entender como o ser humano passa de um estado de menor conhecimento para outro de maior conhecimento." (1997, p. 1).

Uma das contribuições da teoria piagetiana para a área educacional está em apresentar aos professores as etapas do desenvolvimento cerebral, dividido em estágios. De posse desse conhecimento, o professor poderá realizar seu planejamento, bem como as intervenções pedagógicas de maneira mais funcional, o que será de grande valia para o aprendizado integral dos alunos.

Os estágios do desenvolvimento descritos por Piaget propõem, em linhas gerais.

1ㅇ) Estágio sensório-motor (0-2anos), englobando reflexos ou mecanismos hereditários bem como as primeiras tendências instintivas (nutrição) e primeiras emoções; os primeiros hábitos motores, primeiras percepções e primeiros sentimentos diferenciados; inteligência senso-motora ou prática das regulações afetivas elementares e das primeiras fixações exteriores da afetividade;

2ㅇ) Estágio pré-operatório da inteligência intuitiva ( 2 a sete anos), é a fase dos sentimentos interindividuais espontâneos e das relações sociais de submissão ao adulto; 3o) Estágio das operações intelectuais concretas (7 a 12 anos), início da lógica e dos sentimentos morais e sociais de cooperação;

40) Estágio das operações formais e da inserção afetiva e intelectual na sociedade dos adultos (de13 anos em diante) (PETRUCl, 1997, p.3).

Os professores, ao se depararam com esses conceitos ficam relutantes de início, visto que grande parte tem pouco ou quase nenhum conhecimento sobre o assunto. Conhecer as fases do desenvolvimento é de suma importância para o docente, porque o ajudará no momento da sondagem, a detectar a etapa de desenvolvimento de seus alunos, o que contribuirá no momento da elaboração/execução do planejamento.

Ante tal reflexão, Piletti (2011, p. 80), afirma:

Os estudos de Piaget nos mostram que cada fase de desenvolvimento apresenta características e possibilidades de crescimento ocorridas por meio de maturação e de aquisições. O conhecimento dessas possibilidades pode possibilitar aos professores oferecer estímulos adequados a um maior desenvolvimento dos alunos.

Piletti ainda enuncia: "Nesse aspecto, é importante que o educador conheça o nível cognitivo dos seus alunos e suas propriedades seu processo, antes de realizar suas atividades educativas" (2011, p. 80). Isso mostra a importância do trabalho do professor.

Por volta dos anos de 1980, no Brasil, alguns professores, tentando entender as reais contribuições da teoria piagetina para a área educacional, realizaram leituras isoladas de trechos nos quais constava que o ensino deveria estar centrado no aluno, e que o conhecimento precisaria ser construído e, portanto, não transmitido pelo professor. 
A compreensão acerca da construção desse conhecimento na sala de aula sugere que deve ser construída de modo gradativo e não mediante a transmissão pura e simples pelo professor. Assim, a sala de aula passa a ser um laboratório de experimentação e cooperação. A construção do conhecimento (daí a expressão construtivismo), portanto, predispõe a criança à percepção, à observação e à experimentação através da manipulação dos objetos, levando em consideração seu estágio de desenvolvimento (PILETTI, 2011, p.79).

No entendimento de alguns professores, ao ministrar as aulas ficariam livres da necessidade de selecionar os conteúdos específicos e até mesmo de preparar aulas, pois em sua concepção, deveriam esperar, para que em sala de aula surgissem, da fala dos próprios alunos, os conteúdos a serem trabalhados. Assim, a criança aprenderia experimentando, fazendo, observando, enfim, construindo seu próprio aprendizado. Na teoria construtivista,

Privilegiar a atividade do aluno não significa negar a importância do trabalho do professor. Este conserva um papel destacado na ótica construtivista: é aquele que domina o conteúdo (objeto do conhecimento), conhece o processo que se desenvolve em sala de aula, o objetivo almejado, as estratégias possíveis e os próprios alunos. Desse conhecimento decorre a natureza e a qualidade de sua intervenção. Afinal, a ele cabem as tarefas de planejar, atuar, avaliar e reorientar (PETRUCCI, 1997, p. 12).

O papel do professor não é o de mero observador, já que é o detentor do conhecimento formal fundamental no processo de ensino e de aprendizagem. Cabe a ele propiciar práticas pedagógicas que elevem o nível de conhecimento dos alunos por meio de atividades desafiadoras, que o ajudem a sair do senso comum e os levem para o conhecimento científico, tornando-o, assim, alunos com potencial para ser agentes transformadores da sociedade em que estão inseridos.

Outra contribuição da concepção construtivista são as interações. De acordo com Petruci, "Na perspectiva piagetiana, significa organizar situações de sala de aula, que assegurem a interação ativa entre alunos/alunos, alunos/professor, alunos/objeto do conhecimento. Isso não é fácil" (1997, p. 10). O autor assinala ainda que é na relação aluno, professor e objeto que acontece o aprendizado, e é papel da escola oferecer interações de qualidade, que apenas são possíveis graças aos docentes que, conhecendo a etapa do desenvolvimento em que a criança se encontra, problematize e realize intervenções. $O$ discente, por seu turno, é um sujeito ativo na construção do saber.

O processo de interação entre professor e aluno é imprescindível para que o aprendizado aconteça. Isso, contudo, esbarra no erro que o aluno comete ao realizar as atividades propostas pelo professor. Na teoria de Jean Piaget, a conceituação sobre o erro difere da concepção tradicional.

Na concepção tradicional o erro era sinônimo de fracasso, e deveria ser corrigido e punido. Na concepção construtivista "O professor intervém, não para assinalar o erro, punir o aluno, não para apresentar uma rápida resposta certa, mas para problematizar, fornecendo-lhe condições de analisar sua concepção sobre o assunto e alargar sua compreensão." (PETRUCI, 1997, p. 15). O erro é sinônimo de aprendizado, indica em qual etapa do processo de desenvolvimento a criança está e quais intervenções o docente precisa realizar para atingir seus objetivos.

Alguns educadores, ao lerem trechos isolados da teoria piagetiana que versam sobre o "erro", equivocaram-se, imaginando que não deveriam mais corrigir os erros cometidos pelos alunos durante as atividades oportunizadas no dia a dia. Esse fato causou um dano irreparável para as escolas, pois grande parte dos alunos não avançou em seu desenvolvimento, e até mesmo sedimentaram conceitos e ortografia errados.

Atualmente, conforme Dias, "O professor deve compreender o erro como um indicador das coordenações que o sujeito está sendo capaz de fazer em relação ao objeto de conhecimento - 
demonstra em que momento do processo do desenvolvimento cognitivo o sujeito se encontra." $(2016$, p. 7). Ao compreender o erro nessa vertente, a escola passou a usar mais uma contribuição da concepção piagetiana.

As reflexões sobre o desenvolvimento da área cognitiva no ser humano, na perspectiva da teoria piagetiana, trazem à tona a discussão que, se essa teoria, pode efetivamente contribuir no ensino e aprendizagem dos alunos, porque ainda vem sendo utilizada de maneira tão acanhada pelas instituições escolares, se o que se busca é que o aluno, durante o processo de ensino e aprendizagem, possa ressignificar seu conhecimento e ao mesmo tempo ter garantida sua autonomia política, e socioeconômica?

Segundo La Taille, "a autonomia vem da evolução da prática com a consciência das regras" $(1992$, p.49). Atualmente, veem-se crianças, jovens e adultos desrespeitando as regras por falta de consciência de como se viver em sociedade. Agressões verbais e físicas e falta de tolerância com o outro, geram os xingamentos (bullying), e o mesmo se dá por meio do contato virtual (cyberbullying). A sociedade tem regras que nem sempre são seguidas por todos, o que gera conflitos e questionamentos, principalmente a respeito do trabalho que vem sendo desenvolvido nas escolas, para trabalhar juízo moral.

É importante destacar também a sua expressiva contribuição a respeito dos estudos da moralidade humana. Autor da respeitável obra, "O juízo moral na criança", Piaget (1932/1994), influenciado pelas ideias do filósofo Immanuel Kant, que entre outras reflexões dedicou-se também às questões morais, se fundamenta nos pensamentos deste filósofo para desenvolver seu estudo sobre o desenvolvimento da moralidade, a construção e a consciência das regras, destacando nele que a criança passa por duas etapas durante o seu desenvolvimento moral, anteriores à autonomia (regra interna, autorregulação, acordos mútuos, cooperação), são elas a anomia (a= negação; nomia= regra, lei - a moral ainda não se coloca) e a heteronomia (a regra é externa ao Sujeito - há o respeito à autoridade) (DIAS, 2016, p. 5).

Nesse contexto, essa contribuição deixa um norte para a escola, que as crianças, antes de serem autônomas e agirem por sua própria regulação, em um primeiro momento passam pela anomia, que significa não respeitar as regras coletivas, e depois pela heteronomia, em que as crianças são regidas por alguém, e nem sempre fazem algo para satisfazer seus desejos, mas sim para satisfazer o outro, no caso, adultos que a cercam, pais, avós etc.

Nesta direção, ao refletir as etapas de anomia e heteronomia, pelas quais a criança passa durante seu desenvolvimento moral até a chegada à autonomia moral e os tipos de morais implicadas neste processo, surge, essencialmente, a questão educacional que permeia todo este processo, o que nos leva a refletir sobre o quanto a escola é uma instituição fundamental para o indivíduo depois da instituição familiar, pois é nesta que efetivamente iniciam-se os primeiros contatos com regras exteriores às dos pais e membros constituintes das relações parentais (VANNI, 2017, p. 19).

A escola, dependendo do trabalho que realiza, pode chegar ao objetivo de ter adultos que não pensam em ter suas ações pautadas para obedecer e satisfazer outra pessoa, são os que facilmente podem ser manipulados (heterônomos) e os que de alguma forma passam a pensar e agir por seus pensamentos e desejos, porém precisam ter o senso moral para analisar se o que almejam não prejudicará o próximo.

Essas contribuições são importantes durante a formação do aluno, mas nem sempre foram entendidas e utilizadas pelos professores, ou até mesmo consideradas necessárias. Hoje, os professores buscam estudar e compreender melhor a teoria piagetiana e suas contribuições no âmbito educacional. Entretanto, como isso ainda não se tornou realidade, o principal objetivo da educação de formar cidadãos críticos, participativos, com capacidade de criação e autônomos ainda não se efetivou. 


\section{CONCLUSÃO}

O presente estudo possibilitou uma análise das contribuições da teoria de Jean Piaget para a área educacional. Também permitiu reflexões sobre como os professores receberam e colocaram em prática, a teoria piagetiana pensando no ser humano, e de como ele desenvolve a área cognitiva.

A teoria piagetiana não foi pensada, quando de sua criação, para a área educacional, mas versa sobre como o ser humano desenvolve sua capacidade cognitiva. Por esse motivo, a teoria também influenciou a área pedagógica, porque o professor, ciente das etapas de desenvolvimento do cérebro humano, pode perceber em que estágio o aluno se encontra e ser capaz de (re)planejar as aulas que atendam suas necessidades de aprendizado.

Uma mudança considerável para aqueles que almejam uma educação eficiente, que vai desde o ato de planejar, em que o professor é o mediador, e o aluno o ser ativo que constrói o conhecimento por meio das interações, que devem ser de qualidade, tanto com os docentes, com seus pares, ou mesmo com objetos, considerando o erro como parte do processo, para informar o estágio do aprendizado que encontra-se o aluno.

Compreender e utilizar a teoria, os estágios de desenvolvimento são de suma importância durante o processo de ensino e aprendizagem, já que esse conhecimento é essencial para o professor, e desafiador para o aluno, pois ele terá que sair da zona de conforto e buscar a autonomia intelectual, por meio de situações em que deva refletir, pensar, responder por seus atos e buscar soluções para sua vida.

Portanto, essa teoria não se trata de um método, mas sim de uma concepção epistemológica da construção do conhecimento, levando-se a compreensão de como o sujeito aprende e se adapta, servindo de subsídios e estudos para os professores atuarem em sala de aula.

A formação do professor, aliada ao conhecimento da teoria piagetiana, pode e deve contribuir para que os alunos se desenvolvam de forma integral e façam a diferença para vivermos em uma sociedade mais justa, igualitária e com menos desigualdade social.

\section{REFERÊNCIAS}

BARDIN, L. Análise de Conteúdo. Lisboa: Edições 70, 2006.

CHIAROTTINO, R. Z. Psicologia e epistemologia genética de Jean Piaget. São Paulo: EPU, 1988.

DIAS, C.L. Epistemologia e psicologia genéticas - Jean Piaget (1896-1980) Presidente Prudente, 2016. Mimeo.

LA TAILLE, Y. de. Desenvolvimento do juízo moral e afetividade na teoria de Jean Piaget. In: LA TAILLE, Y. de; OLIVEIRA, M. K. de; DANTAS, H. Piaget, Vygotsky, Wallon: teorias psicogenéticas em discussão. São Paulo: Summus, 1992. p.47-73.

PETRUCI, M. das G. R. M. O ensino de história na escola fundamental: a proposta e a prática. Franca: UNESP / FHDSS, 1997.

PILETTI, N. Psicologia da aprendizagem: da teoria do condicionamento ao construtivismo. São Paulo: Contexto, 2011.

SALVADOR, A.D. Métodos e técnicas de pesquisa bibliográfica. Porto Alegre: Sulina Editora, 1991. 
VANNI, V. N. As práticas morais e a aprendizagem de valores e regras: experiência com assembleias em uma escola pública de Ensino Fundamental I. Dissertação (Mestrado em Educação), Unoste, Presidente Prudente, São Paulo, 2017. 